
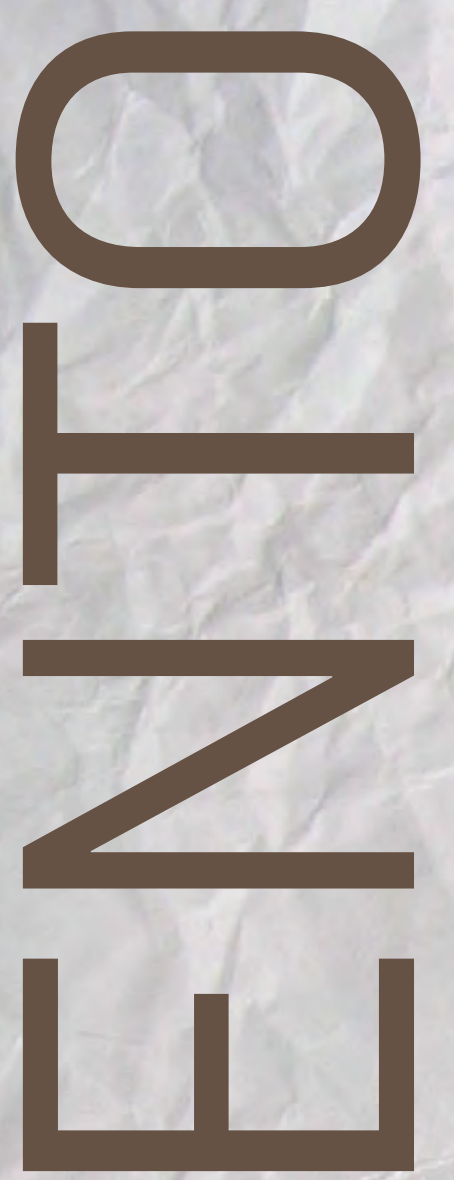

(x)
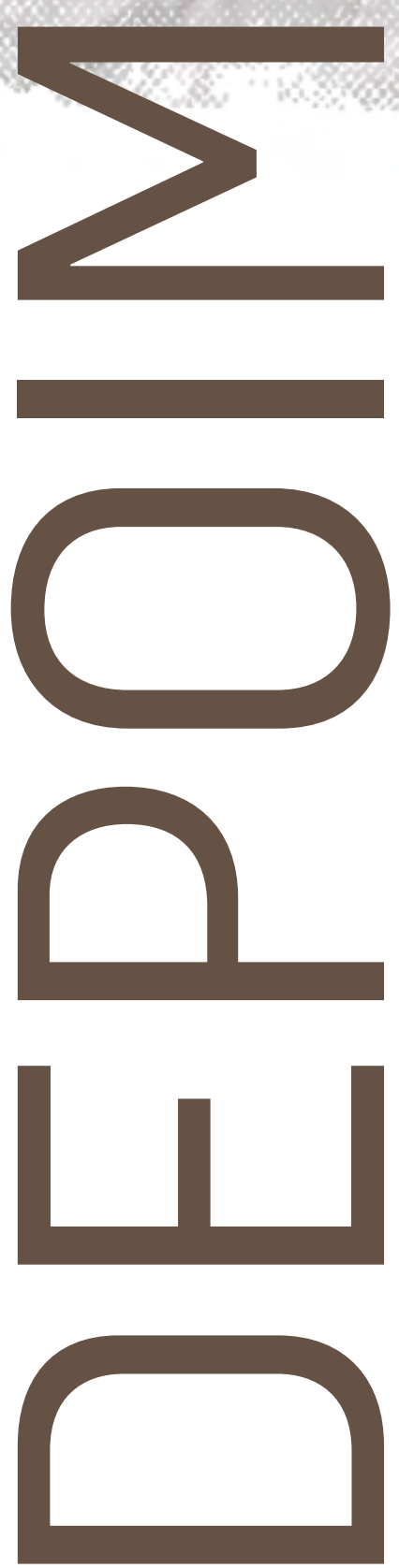

gexis JRA 


\title{
Mídias sociais e risco de imagem
}

\author{
Social media and image risk
}

\section{Medios sociales y riesgo de imagen}

\section{Claudio G. Cardoso' \\ João Abramo² \\ Alexandre Martins ${ }^{3}$ \\ Elizabeth J. S. M. Freitas ${ }^{4}$}

$\mathrm{E}$ ste depoimento antecipa resultados de um estudo sobre análise de mídia, em desenvolvimento no Núcleo de PósGraduação em Administração da Universidade Federal da Bahia, com participação da Altavive e da Orbiit, empresas detentoras de patentes inovadoras no segmento. Oestudo tem examinado mais de três milhões de notícias relacionadas a duas grandes marcas brasileiras, líderes em engenharia e cosméticos. Apresentam-se aqui alguns insights sobre o papel das mídias sociais na análise de mídia, a partir de abordagens desenvolvidas pela pesquisa: o modelo de propagação da marca, a aplicação de algoritmos de monitoramento de audiências em tempo real e a matriz de risco da imagem.

\section{ANÁLISE DE MÍDIA COMO ELEMENTO ESSENCIAL PARA A GESTÃO DE MARCAS}

As novas dinâmicas da produção e publicação de notícias demandam novas soluções para a necessária e indispensável tarefa de analisar a mídia e informar às organizações que detêm marcas expostas ao público sobre fontes e temas que mais as afetam, em que intensidade e com que consequências, positivas ou negativas.

1 Pós-doutor em Ciências da Comunicação pela Escola de Comunicações e Artes da Universidade de São Paulo (ECA-USP). Professor da Faculdade de Comunicação (Facom) e do Núcleo de Pós-Graduação em Administração da Universidade Federal da Bahia (NPGA). E-mail: claudio.g.cardoso@gmail.com.

2 Diretor de Tecnologia da Orbiit Media Analytics. Empresário de comunicação e tecnologia de informação. E-mail: joao.abramo@orbiit.com.br.

3 Jornalista e sociólogo formado pela Pontifícia Universidade Católica de São Paulo (PUC-SP). Diretor de Mídia da Orbiit Media Analytics. E-mail: alexandre.martins@ orbiit.com.br.

4 Doutora em Administração pela UFBA. Presidente da Altavive Comunicação. E-mail: elizabethmfreitas@gmail.com. 
Apesar do novo contexto, nitidamente estabelecido após o advento da internet - com consequências importantes para a atividade jornalística - ter completado mais de duas décadas, os processos de análise de mídia empreendidos pela grande maioria das assessorias não avançaram na mesma medida para fazer frente às novas necessidades.

0 tradicional modelo em três fases, "clipagem > análise > orientações para a organização-cliente", continua em vigor, mesmo que com alguns avanços. É fato que incorporou novas técnicas na primeira fase, com clipagens mais dinâmicas por meio do rastreamento e registro de noticiário publicado na internet (além de rádio e televisão), e também na terceira fase, com a entrega de clipagens e orientações aos clientes por meio de sistemas web mantidos pelas assessorias.

A fase intermediária, de análise, prossegue similar aos modos anteriores, uma vez que continua se debruçando sobre os conteúdos daqueles veículos considerados principais. E aqui está uma questão crucial. Não há muito a avançar na análise enquanto tal, ou seja, a reflexão sobre os conteúdos e as orientações aos clientes. Até aqui, tudo bem. 0 problema reside justamente no conteúdo selecionado pela primeira fase. As clipagens continuam selecionando por meio de dois critérios: a audiência potencial dos veículos (tiragens, pontos de audiência etc.) e a credibilidade atribuída (por consenso ou tradição).

As clipagens vão ficando cada vez mais superadas diante do novo contexto no qual notícias são publicadas em alta velocidade nas redes digitais, acessíveis por meio de dispositivos móveis pela grande maioria das pessoas, em praticamente todos os países. A audiência de cada notícia é bastante divergente, apesar de se encontrarem juntas, ancoradas nos portais onde são publicadas. Notícias aparentemente atrativas, muitas vezes não são muito acessadas, enquanto que, de outro lado, conteúdos publicados em websites de menor tráfego tornam-se sucesso de público a depender do grau de visibilidade e atratividade do tema abordado.

Adicionalmente, nas dinâmicas atuais, não há mais tempo para que alguém identifique a notícia mais relevante, a analise, elabore comentários estratégicos e os publique para, somente então, o cliente - com a sua marca já exposta ao público, em grande velocidade - possa adotar medidas reativas. Esse modelo demonstra grande fragilidade em vários aspectos, com destaque para o processo de identificação da notícia mais relevante, como veremos mais adiante, quando tratarmos da imprecisão dos critérios de seleção.

Nos grandes veículos ${ }^{5}$, mesmo que os pressupostos da relevância por causa da audiência e da credibilidade atribuída sejam diferenciais competitivos, ainda assim, dificilmente uma notícia de impacto lhes permanecerá exclusiva por mais que alguns minutos. Acompanhar exclusivamente aqueles veículos considerados "âncoras" não é mais garantia para obter uma visão ampla e compreensiva dos assuntos em pauta. Impressos de alta relevância - no Brasil, Folha de S.Paulo, O Estado de S. Paulo, O Globo, entre poucos outros - podem manter certa exclusividade sobre uma determinada versão, um determinado enfoque, mas não sobre o assunto em questão. Em pouco tempo a notícia será publicada em algum veículo on-line.

Desse modo, não apenas as temporalidades mudaram, no sentido da velocidade de difusão e da necessidade de reação rápida pelos detentores das marcas. Mudou também a exclusividade dos canais. A clipagem perdeu o sentido, não somente por sua natural lentidão, mas porque o noticiário disperso da web acabará repercutindo a pauta, ao mesmo tempo, concentrando audiência nos portais, e diluindo essa concentração à medida que o tema se torne pauta e, em poucos minutos, centenas de outros veículos de notícias na web, e milhares (se não milhões) de usuários repercutam o tema nas mídias digitais.

5 Referência aos veículos de maior circulação, canais de televisão, emissoras de rádio com grande audiência, jornais de maior tiragem etc. Também tratado mais adiante como 'grande mídia'. 
Vale esclarecer aqui a forma como utilizaremos o termo "pauta", neste depoimento. Ele vai se referir a assuntos razoavelmente circunscritos em uma temática e tratados de forma contínua pela imprensa pelo período de alguns dias, sempre ultrapassando o âmbito da mera "notícia".

Nesse sentido, as principais agências de notícias se encarregarão de veicular uma certa interpretação ou uma certa abordagem do tema em pauta. Tais ângulos e interpretações quase sempre irão se tornar aqueles amplamente adotados pelos demais veículos e repercutidos pelos internautas.

Velocidade e precisão tornam-se, neste novo cenário, valores decisivos para aqueles preocupados com a gestão da qualidade de exposição de marcas. Se, por um lado, a velocidade tem sido enfrentada por meio do monitoramento da mídia on-line em tempo real - com grande atenção dedicada às mídias sociais -, a precisão vem sendo negligenciada.

Ainda não são disseminadas ferramentas de monitoramento da quantidade de acesso às notícias publicadas nos principais veículos on-line. Prossegue o pressuposto da audiência: monitoram-se portais que, supostamente, concentram a maior parte dos acessos. 0 raciocínio estaria correto se o mesmo se aplicasse a todos os conteúdos ali publicados, o que não é fato, nem de longe.

Nossos estudos demonstram diferenças significativas entre notícias publicadas ao mesmo tempo na página de um importante portal, Folha On-line - o mais acessado do país -, onde uma quase atinge a expressiva marca de 11 milhões de pageviews, ao lado de outra com cerca de 15 mil acessos (Tabela 1). A razão para tal discrepância certamente escapa a explicações simplistas e ultrapassa em muito a nossa capacidade de compreensão e as pretensões do nosso estudo.

Tabela 1 - Acesso de duas notícias na Folha On-line em 7/2/2015.

\begin{tabular}{|c|c|c|c|c|}
\hline Seção & Data e hora & Manchete & Endereço URL & Audiência \\
\hline Folha- Poder & $7 / 2 / 15$ & $\begin{array}{c}\text { Com base governista rachada, } \\
\text { Câmara elege novo presidente }\end{array}$ & $\begin{array}{r}\text { http://www1.folha.uol.com.br/ } \\
\text { poder/2015/02/1583457-com- } \\
\text { base-governista-rachada-camara- } \\
\text { elege-novo-presidente.shtml }\end{array}$ & 10.974 .274 \\
\hline Folha - Mundo & $7 / 2 / 15$ & $\begin{array}{c}\text { Hollande e Merkel debatem } \\
\text { crise na Ucrânia com Putin }\end{array}$ & $\begin{array}{c}\text { mundo/2015/02/1586726-hollande- } \\
\text { e-merkel-debatem-crise-na- } \\
\text { ucrania-com-putin.shtml }\end{array}$ & 15.184 \\
\hline
\end{tabular}

Fonte: sistema Media Analytics (Orbiit), acesso em 07/03/2015 (13:34).

Essa tabela acima expõe de forma inequívoca um fenômeno que se opõe à hipótese amplamente utilizada do pressuposto da audiência do veículo como um todo uniforme. 
Adicionalmente, tem-se o caso oposto, onde um veículo com audiências regularmente superiores publica uma matéria sobre o mesmo tópico que um concorrente de menor audiência e o resultado é patentemente o oposto. Na Tabela 2, temos 0 portal R7 com 42 visitas contra quase 3 milhões de pageviews do jornal Zero Hora, tratando precisamente da mesma pauta.

Tabela 2 - Acesso de um mesmo tópico em dois veículos on-line distintos.

\begin{tabular}{|c|c|c|c|c|}
\hline Seção & Data e hora & Manchete & Endereço URL & Audiência \\
\hline $\begin{array}{c}\text { Zero } \\
\text { Hora - Mundo }\end{array}$ & $\begin{array}{l}9 / 5 / 13 \\
14 h 36\end{array}$ & $\begin{array}{l}\text { Primeira ministra negra do } \\
\text { país é vítima de insultos da } \\
\text { extrema-direita italiana }\end{array}$ & $\begin{array}{c}\text { http://zh.clicrbs.com.br/rs/noticias/ } \\
\text { noticia/2013/05/primeira-ministra- } \\
\text { negra-do-pais-e-vitima-de-insultos-da- } \\
\text { extrema-direita-italiana-4132296.html }\end{array}$ & 2.882 .341 \\
\hline $\begin{array}{c}\text { R7 - } \\
\text { Internacional }\end{array}$ & $\begin{array}{l}9 / 5 / 13 \\
14 h 36\end{array}$ & $\begin{array}{l}\text { Primeira ministra negra } \\
\text { da Itália é vítima de } \\
\text { ataques racistas }\end{array}$ & $\begin{array}{l}\text { http://noticias.r7.com/internacional/ } \\
\text { primeira-ministra-negra-da-italia-e- } \\
\text { vitima-de-ataques-racistas-09052013 }\end{array}$ & 42 \\
\hline
\end{tabular}

Fonte: sistema Media Analytics (Orbiit), acesso em 07/03/2015 (14:10).

Diante desse quadro desafiador, o Núcleo de Pós-Graduação da Escola de Administração da Universidade Federal da Bahia, em cooperação com empresas especialistas em análise de mídia, a Altavive e a Orbiit, detentoras de patentes no segmento, vem desenvolvendo uma pesquisa que tem o privilégio de contar com uma base de dados de notícias coletadas desde 2013, hoje com mais de três milhões de registros. Este artigo antecipa alguns resultados deste estudo, previsto para ser concluído em outubro de 2015, no formato de insights.

\section{MODELO DE PROPAGAÇÃO DA MARCA}

0 estudo toma como base a formulação do modelo de propagação da marca, desenvolvida por João Abramo e Alexandre Martins (2015). 0 modelo objetiva estruturar a compreensão dos fluxos de propagação de conteúdos indesejados de modo a identificar pontos de atuação proativa pelas assessorias de comunicação.

A simplicidade do modelo, apresentado de forma preliminar na Figura 1, a seguir, revela justamente a sua engenhosidade. Nela estão apresentadas as camadas de domínio ou perda do controle sobre a informação, além dos atores principais. A figura destaca níveis, começando pelo ambiente de domínio da marca (interno), até o nível mais externo, da opinião pública6 Estes são mediados por duas camadas de mídia: aquela formada pelos especialistas influenciadores do negócio (trade) e, de forma mais abrangente, a imprensa aberta, propriamente dita (grande mídia).

6 Sobre opinião pública, ver: Walter Lippmann (1993, p. 13-18). 
Figura 1: Camadas do modelo de propagação da marca.

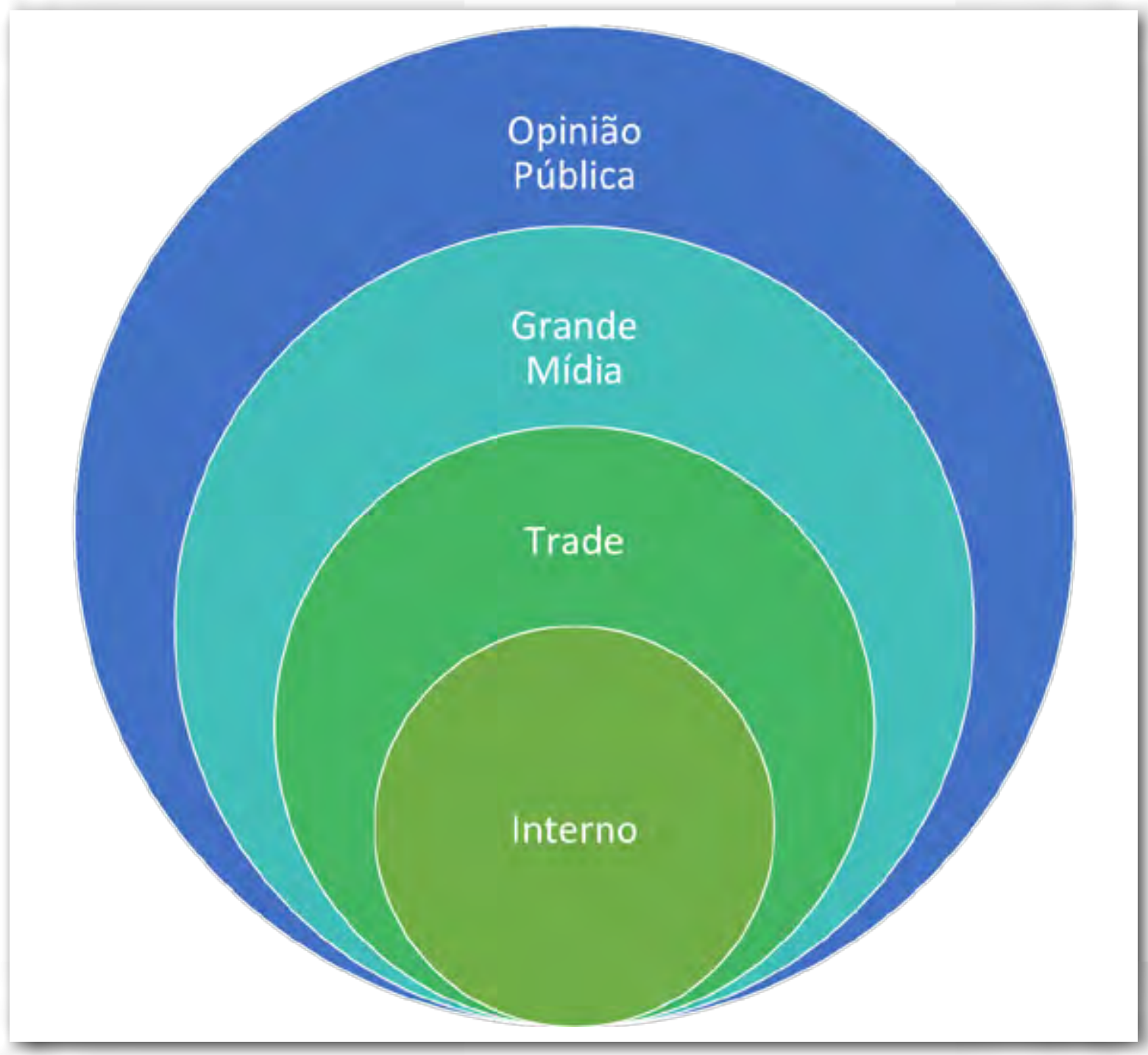

Fonte: Abramo; Martins, 2015.

Contudo, a compreensão desse modelo somente se completa quando dele se destacam as direções dos vetores de 'informação' e 'risco'.

Naquilo que concerne à informação, o domínio interno da marca, ou seja, o conhecimento que o negócio detém sobre seus atributos de valor e posicionamento competitivo, é também o lugar de maior controle. À medida que a exposição da marca se movimenta para camadas mais amplas da sociedade, tal domínio vai se reduzindo até alcançar o que aqui apelidamos de "opinião pública", enquanto sinônimo de espaço coletivo e anônimo de um determinado sentido compartilhado de forma ampla.

Na Figura 2, mais abaixo, a perda de domínio dessa informação está representada pela linha amarela em declínio. Já 0 risco, caminha em direção oposta. Quanto maior a exposição da marca, menor o controle, maior o risco. Este é um raciocínio naturalmente derivado dos fundamentos dos modelos de gestão de risco, que pressupõem maiores perdas potenciais na medida da diminuição do controle sobre as variáveis diretas, o válido para qualquer atividade.

A consequência desse modelo é o crescimento dos custos necessários para reverter quadros de crise de imagem à medida que escalam para as camadas mais externas, escapando do domínio interno, passando pelo trade (especialistas influentes), pela mídia (imprensa não especializada, a "grande mídia") e alcançando a opinião pública, onde sentidos compartilhados dificilmente são revertidos. 
Figura 2 - Modelo de propagação da marca

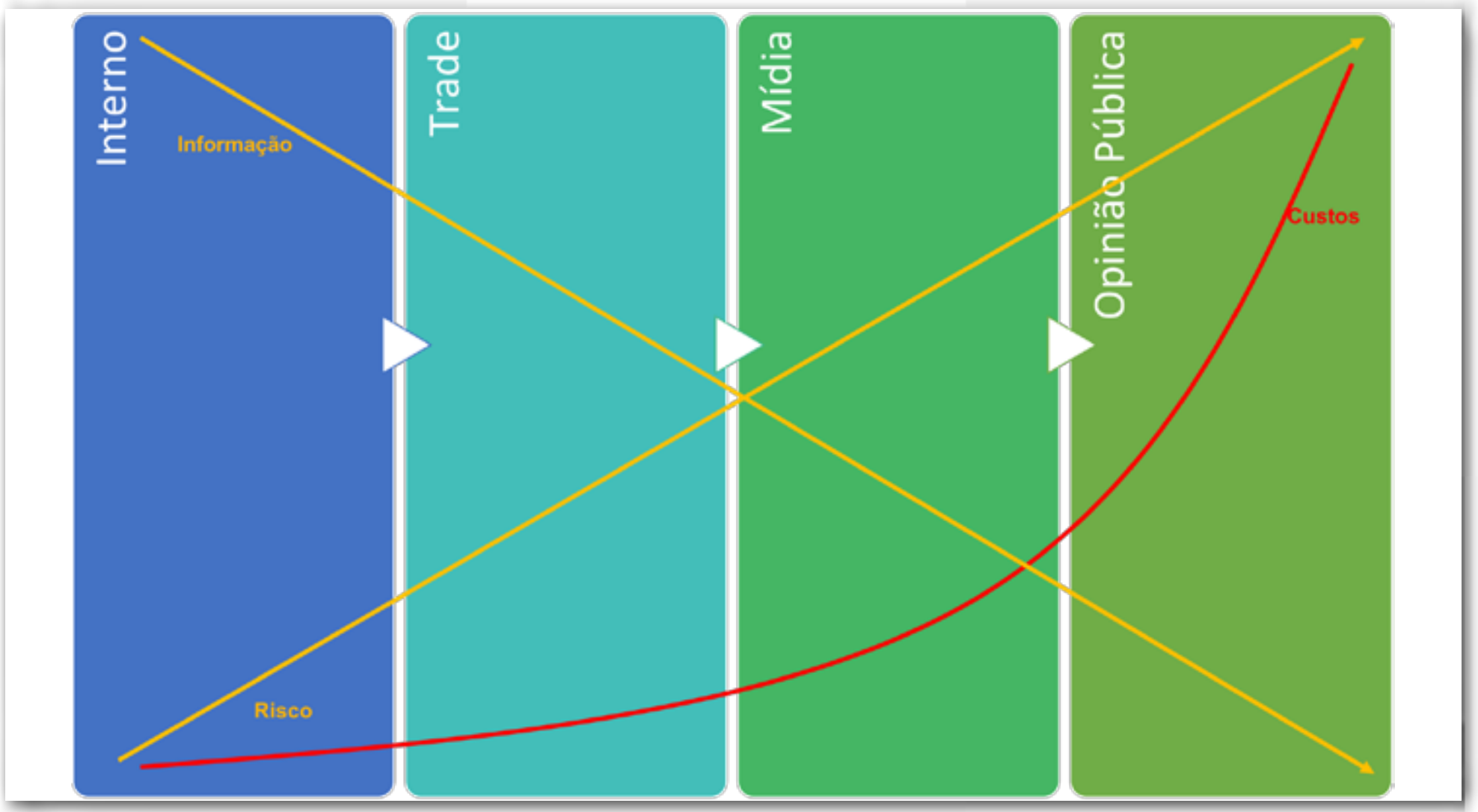

Fonte: Abramo; Martins, 2015.

De posse desse modelo e tendo em perspectiva o propósito do nosso estudo - a saber, desenvolver um novo modelo de análise de mídia, capaz de fazer frente aos seus novos contextos e novas dinâmicas, e a eles responder com alta efetividade para mitigar crises, - prosseguiremos com mais alguns insights até o ponto de trazer as mídias digitais para o contexto do nosso estudo.

\section{IMPRECISÃO ARRAIGADA}

Desde os primórdios, a atividade de análise da mídia buscou identificar correlações de "pesos" das notícias para diferenciar seus impactos sobre a qualidade de exposição das marcas. Estamos nos remetendo ao início dos anos 1980.

Antes dessa época, a "centimetragem" já despontava como medida da relevância de conteúdos coletados pelos serviços de clipagem. 0 cálculo da centimetragem procurava estabelecer comparações entre a exposição da marca na mídia, dita 'espontânea', e a publicidade, esta, naturalmente paga. A base para esse cálculo, bastante utilizado até os dias atuais, é a área coberta no papel pela matéria (textos e, eventualmente, fotos ou figuras), o que, segundo tal raciocínio aplicado por agências de clipagem e assessores de comunicação, torna possível medir o retorno das estratégias de comunicação.

Nessa mesma direção, já em meados dos anos 1980, alguns assessores buscaram caminhos alternativos para conferir maior precisão às medidas de impacto da exposição das marcas na mídia. Criaram tabelas de correlações de pesos dos veículos, baseados nas estimativas de público. Tiragens de jornais e pontos de audiência aferidos pelos institutos de pesquisas passaram a ser utilizados, bem como, a partir daí uma série de atributos dos próprios conteúdos: página da publicação, tamanho e posição nas edições impressas, horário e duração das emissões em rádio e televisão, relevância e credibilidade de quem assinava ou apresentava a matéria, importância do tema para o cliente, dentre outros indicadores. 
ANO $12 \cdot$ NÚMERO $22 \cdot 1^{10}$ sem. $2015 \cdot$ ORGANICOM

MÍDIAS SOCIAIS E RISCO DE IMAGEM

Tal esforço resultou em alguns índices de desempenho da qualidade de exposição da marca na mídia amplamente utilizados por muitas das maiores organizações brasileiras, ao ponto de servirem como indicadores para o reconhecimento e a premiação de executivos cujas áreas de atuação no negócio projetam melhores resultados, aferidos pelos índices.

Apesar dos inegáveis avanços proporcionados por esses modelos, a complexidade e dinâmica do cenário atual desafia, de forma contundente, os indicadores de audiência pressuposta dos veículos. 0 fato é que hoje as fronteiras entre grandes e pequenos veículos são bem menos nítidas. Ao mesmo tempo, a velocidade de publicação foi inteiramente reformulada, bem como o modo e a dinâmica de acesso à informação. Somente esses aspectos já seriam suficientes para questionar os fundamentos de todo o conjunto dessa linha de indicadores.

De imediato, apesar de ainda bastante utilizado, parece razoável admitir que medidas como centimetragem perderam inteiramente sua aplicabilidade. Sem mencionar a reconfiguração do lugar da autoria no jornalismo e as novas dinâmicas proporcionadas pela variedade de formatos de publicação ${ }^{7}$. Estas últimas demandam análises ainda mais complexas, que extrapolam em muito o nosso escopo de pesquisa. Por ora, nos deteremos nos aspectos relacionados a audiência.

Diante desse cenário, a questão da precisão emerge com grande força, uma vez que os melhores indicadores de mensuração da relevância dos conteúdos da mídia, em sua relação com as marcas, tornaram-se insuficientes. É preciso criar novos modelos, de maior precisão.

A contínua utilização do modelo de análise baseado em pesos atribuídos a audiências pressupostas e, pior, o uso da centimetragem como medida de retorno de investimento em comunicação demonstram o quanto esses antigos padrões estão arraigados na mente de assessores e outros profissionais do setor.

Nesse sentido, a análise das mídias sociais indica um novo caminho pela utilização dos registros de acesso ao conteúdo: quantos acessaram, quantos compartilharam, quantos indicaram, quantos reagiram, quantos comentaram. Estes são os dados fundamentais que já foram lançados.

\section{ANÁLISE DE MÍDIA BASEADA EM DADOS PRECISOS}

Medir a audiência com precisão é um antigo sonho de praticamente toda a indústria relacionada à mídia. Seja a publicidade, o jornalismo, o marketing político, ou quaisquer outras atividades que incluam veiculações midiáticas das mais diversas naturezas, todas buscam medir com a máxima precisão o público atingido, seu perfil, além da maior quantidade possível de informações sobre as formas de recepção, apropriação e transformação das mensagens.

A internet, em boa medida, viabilizou tal sonho ${ }^{8}$. Nela, cada acesso deixa rastros. Cada consulta registra o visitante. Cada comentário ou compartilhamento, qual a duração da consulta, e outros dados de localização, número de seguidores em mídias sociais, podem também ser identificados: idade, gênero, classe social, educação, estado civil, interesse e indicadores comportamentais.

Curiosamente, na última década ocorreu uma imensa proliferação de agencias dedicadas à análise de mídias sociais, 7 Ver a interessante discussão sobre autoria em blogs e no jornalismo empreendida por Marcos Palacios e Paulo Munhoz (2007).

8 Para uma visão geral do assunto, ver Manuel Castells (2001). 
notadamente Facebook e Twitter e, mais recentemente, Instagram, Youtube, Flickr, Google+, Linkedln, Pinterest e outras. Surpreendentemente, não se encontra facilmente esse nível de interesse e investimento para análises similares da grande mídia na internet. A precisão ficou do lado das mídias sociais, talvez pela intrínseca conexão com seu nascedouro, a internet, campo de domínio mais próximo das ciências da informação que do jornalismo ou da gestão. 0 mundo do jornalismo, nessa perspectiva, continua em segundo plano: impreciso e ainda refém da sua origem, nos impressos e na rádio e na televisão, de difícil aferição do público atingido.

Contraditoriamente, o nosso estudo tem revelado de forma consistente o quão remoto é o movimento das mídias sociais de pautarem a grande imprensa. Lembramos a nossa abordagem do termo como um fenômeno de cobertura contínua pela imprensa. Dentre milhões de registros, são virtualmente desconhecidos casos em que uma notícia de grande impacto e duração tenha sido primeiramente publicada em uma mídia digital. Sabe-se detalhadamente sobre as audiências das mídias sociais e muito pouco daquelas da imprensa.

Em nossa análise, consideramos os blogs de jornalistas, cronistas, analistas reconhecidos e articulistas como parte integrante da imprensa, na camada "trade", segundo o modelo apresentado nas figuras 1 e 2. Estão incluídos nessa categoria os twits publicados pelos grandes veículos para atrair audiência aos seus portais de notícias, bem como aqueles publicados por especialistas, apontando para suas colunas e seus blogs.

A grande mídia continua, ou deveria continuar sendo o centro das atenções dos assessores de comunicação responsáveis pela preservação e pelo fortalecimento de marcas. É nesse campo que acontecem a maioria esmagadora dos adventos ameaçadores e as melhores oportunidades de exposição positiva. Contudo, o noticiário na web, operado sobre a mesma plataforma das mídias sociais que, como vimos, possibilita o registro detalhado dos acessos, não tem merecido o mesmo tratamento meticuloso de aferição precisa da sua audiência.

Oportunamente, a Orbiit desenvolveu o Media Analytics ${ }^{9}$ sistema que contém um algoritmo capaz de identificar em tempo real o número de acessos individuais ao noticiário da grande mídia na internet. Com margem de aproximação estimada em $15 \%$, oferece ao nosso propósito um instrumento de pesquisa de alta qualidade.

Uma vez de posse desse instrumento, as análises de mídia avançaram rapidamente, até o próximo desafio. Retomando a Figura 2, notamos que a camada "mídia" passou a ser compreendida de forma bastante satisfatória. De uma vez, passamos a saber o que estava sendo mais lido, o que estava sendo colocado de lado - às vezes de forma inesperada e surpreendente, - quais veículos são, de fato, mais acessados, por quem, em quais horários, quais as pautas mais atrativas. Além disso, passamos a compreender com nitidez o comportamento dos súbitos crescimentos de audiência e também a identificar previamente quando uma pauta não vai se tornar relevante para o grande público.

Parece presunçoso, mas, assim como os jovens analistas das mídias sociais, passamos a avaliar com riqueza de detalhes a audiência de cada notícia, não importando o volume de tráfego do veículo. Ao mesmo tempo, constatamos que o noticiário na web publica rigorosamente todas as pautas relevantes. Notamos alguns casos, bastante raros, em que um veículo impresso especialista publica algo inédito. Contudo, em poucos minutos a notícia repercute na web. Assim, monitorar impressos com a finalidade de clipagem, tornou-se, em nossa opinião, uma atividade penosa, de custo elevado, lenta e desnecessária, uma vez que a web se encarregará de trazer à luz seus conteúdos relevantes em questão de minutos.

Resta compreender de que forma diferentes pautas atingem as marcas que se pretende monitorar. Para fazer frente a essa importante questão, lançamos mão do estudo sobre gestão do risco de imagem empreendido desde 2008 por Cláudio

9 Ver: <http://mediaanalytics.com.br>. 
Cardoso e Márcio Polidoro (2011). Estes autores acreditam que a análise dos impactos das notícias passa pela compreensão das forças e fraquezas da própria marca. Ademais, é preciso tornar menos imperiosa a variável "audiência". Nem tudo que alcança grandes públicos afeta a marca de forma contundente.

\section{MATRIZ DO RISCO DE IMAGEM}

A matriz do risco de imagem é um desdobramento da abordagem proposta por Cardoso e Polidoro (2011, p. 12), cujo propósito declarado à época era superar

paradigmas amplamente adotados em todo o mundo da comunicação nas organizações (...), a ampla adoção das metodologias de gestão de crise, que em certa medida refletem desconhecimento de uma nova forma de atuar, (..) uma metodologia a ser criada com a ambição de (..) mitigar riscos com a imagem institucional por meio da identificação de pontos críticos de um empreendimento, acompanhada de uma atuação proativa, antecipatória, planejada, premeditada, onde aspectos positivos do negócio são ressaltados, ao invés de uma reação ao negativo.

Segundo os autores, o segundo paradigma a ser enfrentando seria "uma nova abordagem dos investimentos em comunicação a partir de uma mentalidade atuarial que compreende os custos de comunicação 'como um seguro', e a imagem como mais um item nos cálculos de risco do negócio como um todo" (Cardoso; Polidoro, 2011, p. 12) ${ }^{10}$.

Desde então as nossas pesquisas indicaram a necessidade de mapear riscos de imagem a partir da visão estratégica das próprias organizações para o posicionamento das suas marcas. Antes de prosseguir sobre o modelo apresentado na Figura 3, a seguir, é preciso destacar uma sutileza que pode passar despercebida. Assumir como ponto de partida as estratégias de posicionamento da marca representa uma mudança importante em relação aos métodos aplicados na gestão de crises.

Figura 3 - Modelo para análise de mídia baseado em "risco e audiência"

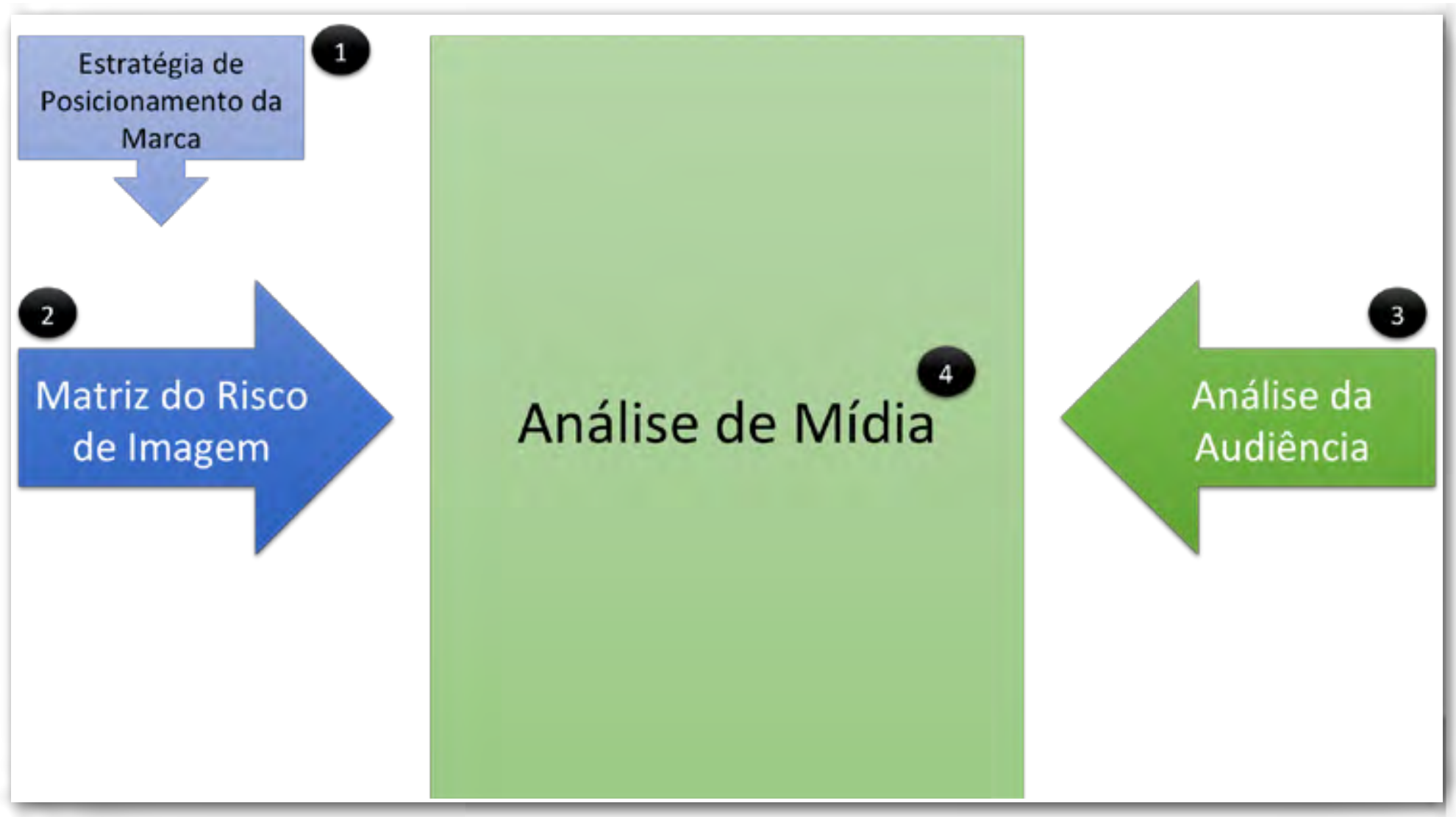

Fonte: elaborada por Claudio Cardoso, em 2015. 
Habitualmente o mapeamento dos riscos obedece ao movimento de fora para dentro, isto é, a partir da observação da cobertura realizada pela mídia, identificam-se as pautas a serem revertidas ou mitigadas. O que aqui se propõe éjustamente 0 inverso. Primeiramente identificar os aspectos mais ameaçadores à marca para daí estabelecer critérios de monitoramento e atribuição de relevância para os conteúdos publicados.

É o movimento de dentro para fora, ou seja, a partir do interno para as demais camadas, conforme preconizado pelo modelo de propagação da marca (Figura 2) como o espaço de maior informação, maior controle e menor risco. Estimulados pelas primeiras descobertas do estudo sobre a gestão de risco da imagem, partimos para o desenvolvimento de uma matriz de risco capaz de ser combinada aos algoritmos de monitoramento da audiência.

Dessa combinação espera-se obter uma composição de "pesos" mais precisa e dinâmica, uma vez que utiliza números precisos da audiência com os direcionamentos fornecidos por aqueles que detém a informação do negócio.

A Figura 3 apresenta os quatro momentos para uma nova proposta de análise de mídia. Parte-se da identificação das estratégias de posicionamento da marca. São elas que vão definir quais pautas serão mais caras aos interesses da organização e que mais a afetam, positiva ou negativamente. Em seguida, o segundo momento, com a elaboração da matriz de risco propriamente dita, um exercício meticuloso de identificação e registro dos ambientes e dos fatores de risco, um a um. 0 terceiro momento é o monitoramento propriamente dito, que inclui as etapas de rastreamento, identificação, coleta e registro do número de visitantes de cada conteúdo. Para, enfim, realizar o quarto momento, de análise da mídia, propriamente.

A metodologia criada para construir a matriz de risco é simples, porém trabalhosa. 0 melhor caminho para esclarecê-la é, seguramente, por meio de uma ilustração.

Tomemos como exemplo um restaurante. Parte-se da identificação dos ambientes de risco da sua imagem. De forma um tanto precipitada, apenas para o propósito de ilustrar o método, podemos assumir que o primeiro ambiente de risco seja 0 do relacionamento com clientes. 0 segundo poderia ser o relacionamento com fornecedores; 0 terceiro, com 0 ambiente interno da operação, e daí por diante: ambiente de relacionamento com órgãos de fiscalização, com a mídia, concorrentes e outros. Para melhor compreensão do modelo, ver a Tabela 3, a seguir.

Tabela 3 - Ilustração de uma matriz de risco.

\begin{tabular}{|c|c|}
\hline Ambientes de risco & Fatores de risco \\
\hline Ambiente de relacionamento com clientes & $\begin{array}{l}\text { - } \quad \text { Deficiências no setor de reservas } \\
\text { - } \quad \text { Insatisfação com atendimento }\end{array}$ \\
\hline Ambiente de relacionamento com fornecedores & $\begin{array}{l}\text { - } \quad \text { Fornecedores com grande poder de barganha } \\
\text { - } \quad \text { Fornecedores pouco comprometidos }\end{array}$ \\
\hline Ambiente da operação (restaurante) & $\begin{array}{l}\text { - } \quad \text { Equipe desqualificada } \\
\text { - } \quad \text { Equipe descomprometida }\end{array}$ \\
\hline $\begin{array}{l}\text { Ambiente de relacionamento com órgãos } \\
\text { reguladores e fiscalizadores }\end{array}$ & $\begin{array}{l}\text { - } \quad \text { Fiscalização muito presente } \\
\text { - } \quad \text { Dificuldades de obtenção das normas de regulação }\end{array}$ \\
\hline Ambiente de mídia e marketing & $\begin{array}{l}\text { - } \quad \text { Desgaste na relação com veículos ou colunistas } \\
\text { - Imprensa atuante no setor de gastronomia }\end{array}$ \\
\hline
\end{tabular}


ANO $12 \cdot$ NÚMERO $22 \cdot 1$ ํㅗ. $2015 \cdot$ ORGANICOM

MÍDIAS SOCIAIS E RISCO DE IMAGEM

\begin{tabular}{|l|l|}
\hline \multicolumn{1}{|c|}{ Ambientes de risco } & Fatores de risco \\
\hline Etc. & $\cdot \quad$ Fatores de risco do ambiente etc. \\
\hline
\end{tabular}

Fonte: elaborada pelos autores, em 2015.

Naturalmente, existem muitas maneiras de mapear aspectos ameaçadores, a partir de entrevistas com aqueles que conhecem profundamente o negócio. Este que aqui apresentamos, criado por uma grande empesa de engenharia brasileira e adotado em nosso estudo, é apenas um dos caminhos possíveis.

O importante não é tanto a forma de sistematizar o registro dos riscos, mas a obediência ao princípio do modelo de propagação. São os detentores da marca e de suas estratégias de posicionamento que devem definir aquilo que é relevante e, consequentemente, o quanto "pesa" cada mensagem publicada pela mídia. Jamais o caminho inverso, de adotar a pauta da mídia como linha de ponderação de sua análise. A audiência, como vimos, deve ser ponderada pelos interesses da marca, não o contrário.

\section{MÍDIAS SOCIAIS NA ANÁLISE DA MÍDIA}

Ao contrário do que muitos pensam, mídias sociais raramente pautam a grande mídia. Os nossos estudos, que utilizam mais de três milhões de notícias relacionadas a duas grandes marcas brasileiras, líderes em engenharia e cosméticos, demonstram esse fenômeno de modo bastante consistente e sistemático.

São monitorados trezentos veículos brasileiros na web, e mais de seiscentos em toda a América Latina espanhola. Desde 2013 foram identificados três casos em que um post primeiramente veiculado numa mídia social por um usuário nãoespecialista (ou seja, de fora do trade) acabou pautando a grande imprensa. Em termos numéricos, estamos tratando de três em três milhões, ou seja, uma probabilidade estatística de 0,0001\%.

Contudo, existem outras razões bastante relevantes para que as mídias sociais devam ser monitoradas com toda a atenção e cuidado, em tempo real. Para os nossos propósitos, extraímos desta categoria - "mídias sociais", como sinônimo de ambiente de comunicação para usuários de fora da imprensa ou especialistas - todos os twits publicados pelo trade. Assim, neste estudo, "mídias sociais" são responsáveis pelas demais publicações, nas mais variadas redes mencionadas acima.

Dito de outro modo, a monitorar o trade com grande atenção, aprendemos que o suporte midiático utilizado passa para um plano secundário. Se o trader, o influenciador de pautas, utiliza o Twitter, o Facebook, um blog, ou publica em sua coluna de um jornal de grande circulação, ou, ainda, se é locutor de rádio, pouco importa para os nossos fins. 0 veículo utilizado não é mais critério distintivo do grau de relevância do monitoramento, mas, sim, o grau de influência do próprio publisher.

Desse modo, quando afirmamos que "mídias sociais", em geral, não produzem pautas de alto impacto sobre as grandes marcas, estamos retirando dessa conta os traders. Assim, mídias digitais, quando utilizadas pelo "grande público", quase sempre apenas repercutem as pautas produzidas pelos influenciadores.

Contudo, as mídias sociais desempenham papéis de destaque em relação às grandes marcas, notadamente em três dimensões, conforme ilustrado pela Figura 4, a seguir. 
Figura 4 - Dimensões das mídias sociais em relação às grande marcas.

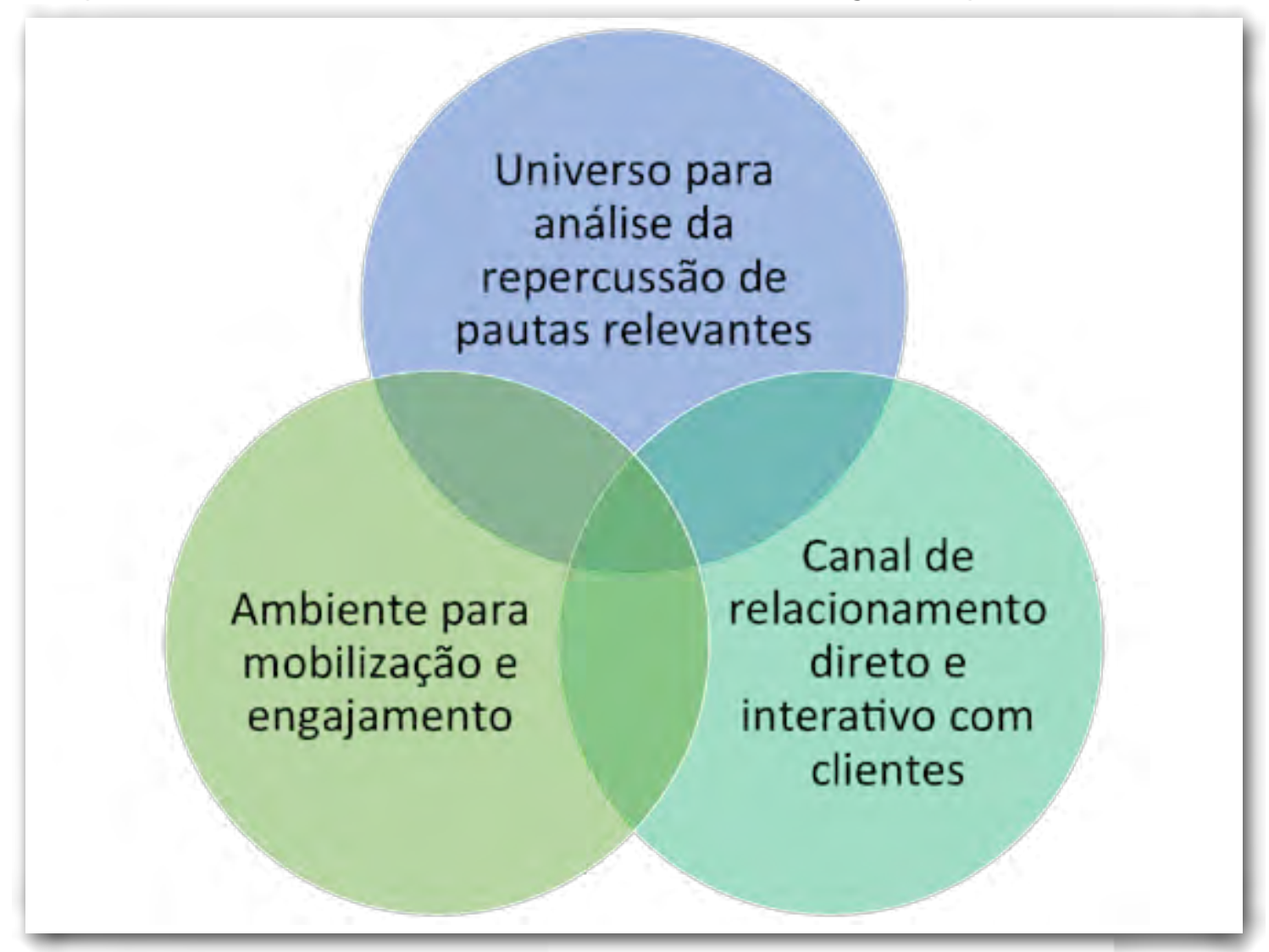

Fonte: elaborada por Claudio Cardoso, em 2015.

No presente trabalho nos limitaremos a apresentar o modelo acima, sem aprofundar as dimensões apresentadas. Tal discussão será levada a cabo em um novo ensaio em elaboração.

Para os propósitos de análise de mídia por assessores de comunicação, a nossa pesquisa demonstra, até mesmo antes da sua conclusão, a urgência da criação de modelos para a definição de critérios de alertas. É imprescindível sistematizar avisos preferencialmente encaminhados para assessores e executivos por meio de mensagens por e-mail ou para telefones celulares (SMS, WhatsApp ou outros aplicativos) - pela definição de limites para adventos das seguintes naturezas: menções a pautas muito agressivas associadas aos fatores identificados na matriz de risco; ritmo acelerado de crescimento de um determinado tema; número elevado de "curtidas" de um determinado postrelacionado à marca; ou número elevado de compartilhamentos.

Vale lembrar que um dos critérios fundamentais para todos esses "gatilhos" dos alertas é o critério de tempo. Qual o período definido para estimar que um determinado número de ações seja considerado alarmante? Este é um critério fundamental que, em nossa experiência, deve ser definido após estudo de situações reais.

A depender do alcance da marca e do número de clientes a ela relacionados, critérios mal definidos acabam por provocar uma avalanche de alertas, tornando-os praticamente impossíveis de administrar e conduzir comunicadores à melhor tomada de decisão.

Outros critérios relativos ao potencial de audiência de determinados usuário - tratados detalhadamente pelas agências especializadas, os "influenciadores" ou "publishers" - são os números de seguidores diretos, e os seguidores dos seguidores. Entram nesta conta os estudos do perfil de ambos grupos de seguidores (de primeiro nível ou seguintes), uma vez que muitos deles podem fazer parte do trade. Caso isto ocorra, esses usuários merecerão acompanhamento mais direto e, eventualmente, critérios de alertas específicos. 
Destaca-se 0 importante trabalho desenvolvido por agências de mídias digitais na identificação de perfis de usuários visando ao estabelecimento de relações comerciais com seus clientes. São identificados, além daqueles mencionados mais acima, dados sobre perfil de compras, hábitos de consumo, visitas a websites de compras, até o detalhe do item escolhido, e muitas outras informações estratégicas para vendas.

Do ponto de vista da gestão do risco de exposição de marcas, o monitoramento das mídias sociais serve, de modo privilegiado, para avaliar o impacto e a repercussão das notícias veiculadas pelos grandes meios. Adicionalmente, o monitoramento das mídias sociais serve também ao propósito da gestão do relacionamento com clientes e com a sociedade em geral. Usuários costumam endereçar queixas e reclamações por meio delas.

Este breve depoimento buscou antecipar alguns resultados de quase três anos de análises da mídia, no Brasil e na América Latina espanhola, ainda em desenvolvimento no Núcleo de Pós-Graduação em Administração da Universidade Federal da Bahia, com o apoio de mecanismos de monitoramento desenvolvidos pela Altavive e pela Orbiit.

Com final previsto para o início de 2016, a pesquisa "Automação aplicada a análise de mídia" prevê a publicação de estudos fundamentados por análises estatísticas no período de doze meses subsequentes à sua conclusão.

\section{REFERÊNCIAS}

ABRAMO, João; MARTINS, Alexandre. (2015). Modelo de propagação da marca. [Notas de encontro]. Inédito. São Paulo, 2015.

CARDOSO, Claudio; POLIDORO, Márcio. Gestão de risco da imagem institucional. In: CONGRESSO CIENTÍFICO BRASILEIRO DE COMUNICAÇÃO ORGANIZACIONAL E DE RELAÇÕES PÚBLICAS, V, São Paulo, 2011. In: Anais do V Abrapcorp. São Paulo Editora Schoba, 2011.

CASTELLS, Manuel. The internet galaxy. Oxford: Oxford Press, 2001.

LIPPMANN, Walter. [1922]. Public opinion. New York: Halcyon Classic Series, 1993.

PALACIOS, Marcos; MUNHOZ, Paulo. Fotografia, Blogs e Jornalismo na nternet: Oposições, Apropriações e Simbioses. In: BARBOSA, Suzana (Org.). 0 jornalismo digital de terceira geração. Covilhã, Portugal: Labcom Books, Universidade da Beira Interior, 2007. Disponível em: <http://www.almanaquedacomunicacao.com.br/ wp-content/uploads/2011/10/FotografiaBlogs-e-Jornalismo-na-Internet.pdf>. Acessado em: 07 mar. 2015.

Artigo recebido em 10.03.2015 e aprovado em 04.05.2015. 